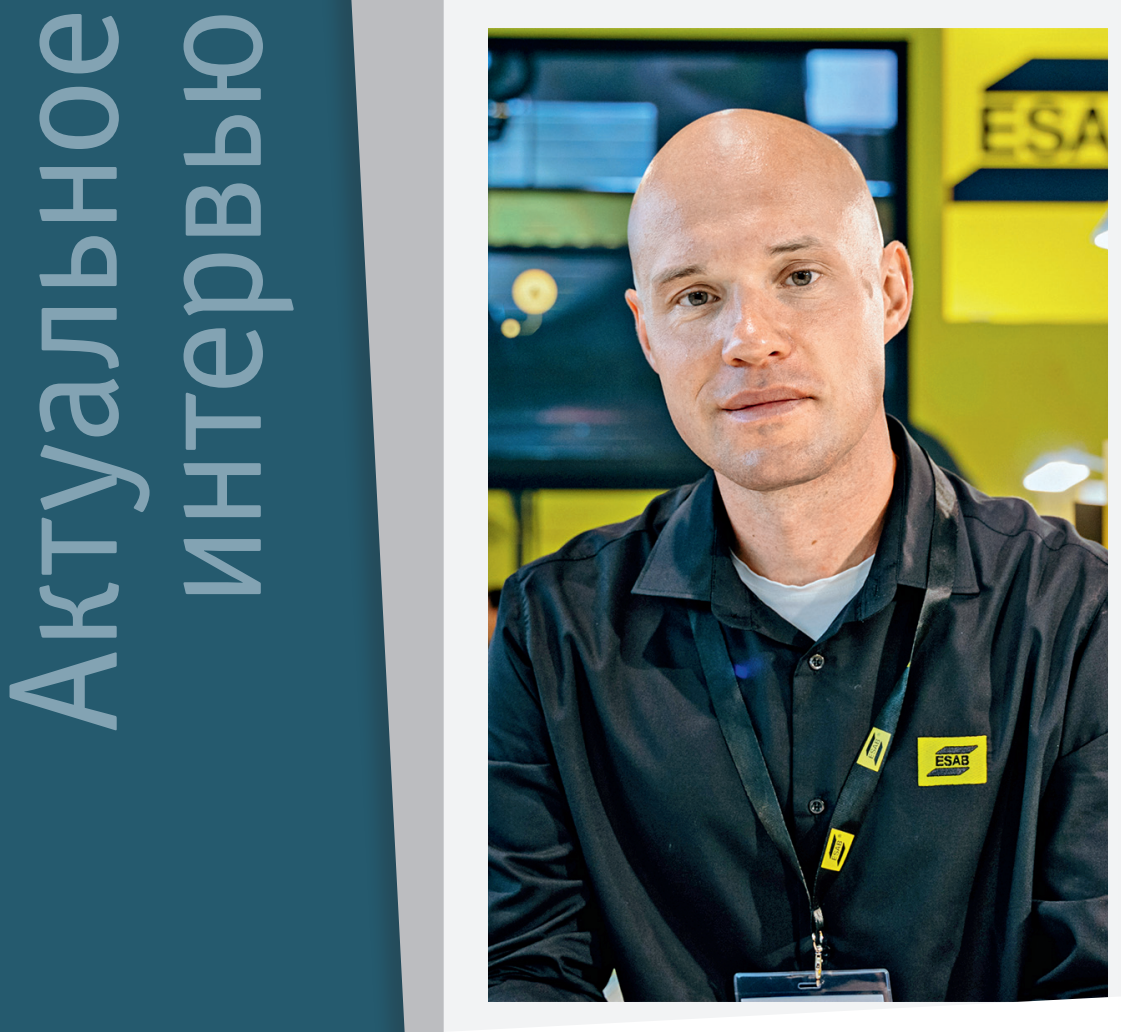

В условиях нестабильной экономической ситуации в мире и ограничений, вызванных пандемией, рынок вновь претерпел изменения. Все больше компаний ищут возможности сократить существующие расходы и оптимизировать экономику своих производств. Так, например, многие компании стали чаще обращаться за сервисными услугами, нежели раньше, когда риск простоев не был столь значимым. Сегодня в оборудовании особенно ценится надежность, качество, простота, а главное экономическая доступность. 0 том, как на эти потребности рынка отвечает компания $\mathrm{ESAB}$, рассказывает Андрей Седов, начальник отдела стандартного оборудования ESAB.

\title{
ОТ СЛОЖНОГО К ПРОСТОМУ - ПУТЬ К ЭФФЕКТИВНОСТИ
}

\section{- Андрей, расскажите, пожалуйста, как компа- нии ESAB удается удержиВать лидирующие позиции на рынке?}

- Индустриальный рынок стремительно меняется, а конкуренция между компаниями, как следствие, растет. Способность быстро и легко адаптироваться к новым реалиям - определяющий фактор для всех игроков такого рынка.

Компания ESAB, как известно, один из лидеров в области производства оборудования и расходных материалов для сварки и резки, она широко известна на мировой арене своими разработками и инновациями. Да и как иначе, ведь она была основана человеком, создавшим современную нам сварку как таковую - Оскаром Челльбергом, запатентовавшим первый в мире покрытый сварочный электрод.

Очевидно, что стремление к инновациям - отличительная черта компании и по сей день, но есть и другие, не менее значимые, в том числе умение слышать, анализировать и прогнозировать потребности рынка и своих клиентов. В совокупности все это позволяет ESAB оставаться в лидерах рынка уже более 100 лет.

\section{- Как изменился потребитель за последние} несколько лет?

- Можно сказать, что покупатель становится более рациональным и расчетливым. Это очевидная тенденция во всем мире, причин возникновения которой достаточно много. В частности, все больше людей осознают потребность в экономии ресурсов, хотя бы потому, что чрезмерный их расход существенно отражается на экологии, а значит, косвенно и на каждом из нас. Кроме того, современный потребитель покупает оборудование, только убедившись в рентабельности этого приобретения, его надежности, преимуществах.

\section{- Как Ваша компания подстраиВается под эту тенденцию?}

- Мы понимаем, что сложное и многофункциональное сварочное оборудование нужно далеко не всем, зачастую достаточно куда более простых, но надежных решений, именно поэтому сегодня мы сконцентрированы на развитии стандартных продуктов.

Так, например, этой осенью мы выпустили на рынок новые сварочные источники - 
Fabricator ЕМ 400і и Fabricator ЕМ 500i. Fabricator это серия инверторных источников питания для сварки MIG/MAG сплошной и порошковой проволокой, а также ручной дуговой (ММА) сварки в тяжелых условиях.

Универсальность новых источников позволяет использовать их как для работ в производстве или монтаже металлоконструкций, так и для ремонтных работ, например, спецтехники. Универсальный и доступный продукт, который, на наш взгляд, будет востребован среди самых разных по величине и направлению деятельности предприятий.

\section{- Можно ли сказать, что пополнение В линейке призВано стать ответом на потребности боль- шинства?}

- Разработка новых источников Fabricator EM 400i и Fabricator EM 500i стала результатом глубокого анализа потребностей рынка и востребованности наших продуктов. Так, мы заметили, что особенно высоким спросом пользуется аппарат Warrior - не самый технологичный и функциональный в нашем ассортименте, однако чрезвычайно надежный, универсальный и недорогой.

Чтобы повторить успех Warrior, мы сконцентрировались на создании нового решения с теми же преимуществами. Чтобы снизить затраты на производство, сохранив основной функционал и качество оборудования, мы убрали функцию дополнительных настроек ММА-режима, режим строжки и цифровой дисплей. В результате, получилось недорогое, но качественное, надежное и эффективное решение с обширными возможностями применения.

- РазВитие такого рода стандартных продуктов, на Ваш Взгляд, не тормозит скорость разВития технологий?

- Наоборот - заставляет искать оригинальные пути решения распространенных производственных задач, не зацикливаться на чем-то одном.

Так, мы добавили в сварочные источники Fabricator принципиально новую функцию повторяющегося четырехкратного режима, которая позволяет переходить от одних, заранее сохраненных режимов, к другим одним нажатием триггера на горелке. Безусловно, этим мы сэкономим пользователю всего пару секунд, которые он потратил бы на перестройку вручную, но в долгосрочной перспективе секунды складываются в измеримую выгоду для наших заказчиков. Для нас важно, чтобы продукт обеспечивал заказчику уверенность в надежности, непрерывности и экономической эффективности его производственных процессов.

С А. Седовым беседовала О. Лаврентьева.
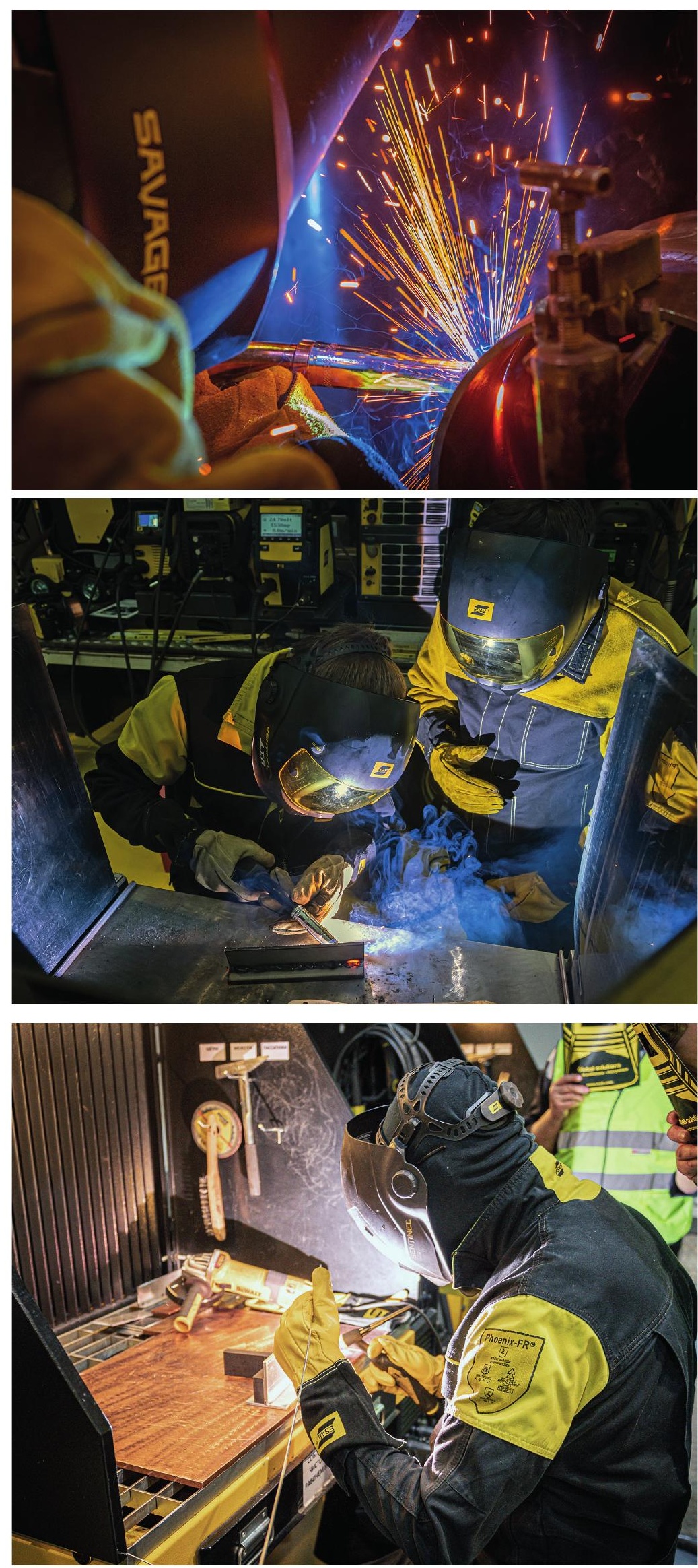